\title{
Personality Factors in Exercise Addiction: A Pilot Study Exploring the Role of Narcissism, Extraversion, and Agreeableness
}

\author{
Rebecca H. Cook ${ }^{1}$ • Mark D. Griffiths ${ }^{1}$ • \\ Halley M. Pontes ${ }^{1}$
}

Published online: 17 May 2018

(C) The Author(s) 2018

\begin{abstract}
Despite the increased evidence and acceptance of exercise being classed as a behavioral addiction, there is limited research examining personality characteristics within exercise addicts. The purpose of this study was to examine three personality traits (narcissism, extraversion, and agreeableness) and to examine their role in exercise addiction. The sample comprised 114 voluntary participants (74 females and 40 males) who completed the (i) Exercise Addiction Inventory, (ii) Narcissistic Personality Inventory, and (iii) Ten-Item Personality Inventory, as well as demographic questions and questions concerning their engagement and intensity levels of exercise. Results indicated a low incidence of individuals who were classed as at risk of exercise addiction (7\%), but a high incidence of symptomatic individuals (75\%). Results suggested that extraversion and narcissism may be underlying factors in exercise addiction with no effect for agreeableness. Exercise engagement and intensity were also related to exercise addiction. Further research examining the relationship between personality types and exercise addiction may be useful in identifying individuals at risk for developing exercise addiction.
\end{abstract}

Keywords Exercise addiction $\cdot$ Personality factors $\cdot$ Narcissism $\cdot$ Extraversion $\cdot$ Agreeableness

Exercise participation is typically seen as a healthy behavior that enhances both physical and psychological wellbeing (Fox 1999). However, excessive physical activity can have detrimental effects where it may manifest into a potential addiction if it starts to become a compulsive activity in an individual's day-to-day life (Hausenblas and Downs 2002). The shift in how addiction has changed has been significant in the last few decades with the DSM-5 (American Psychiatric Association 2013) altering the previous category of "substance-related disorders" to one that also considers behavioral addictions. At present, the only behavior that is officially

Halley M. Pontes

contactme@halleypontes.com

1 International Gaming Research Unit, Psychology Department, Nottingham Trent University, 50

Shakespeare Street, Nottingham NG1 4FQ, UK 
recognized as a behavioral addiction in the DSM-5 is gambling disorder (although Internet gaming disorder is included in the DSM-5 appendix), where it was moved from "impulsive control disorders" to the newly reclassified category "addiction and related disorders" (Reilly and Smith 2013). The DSM-5 suggested other disorders such as Internet addiction and sex addiction may be classed as future behavioral addictions, but only if reliable empirical research confirms the existence of such conditions (Reilly and Smith 2013). The belief that addiction now covers a variety of behaviors such as exercise has led to many theories and contributing factors of addiction. One of the underlying contributing factors in the acquisition, development, and maintenance of addiction may be personality and specific traits (Gossop and Eysenck 1980) including narcissism (Akehurst and Thatcher 2010; Miller and Mesagno 2014; Spano 2001).

There is growing evidence that narcissism may be associated with exercise addiction symptoms (Miller and Mesagno 2014; Spano 2001), although findings from recent literature are inconclusive. A narcissistic personality has been described as a pattern of characteristics that are present in an obsessive behavior whereby individuals become very self-centered as they crave opportunities for self-enhancement and excel when being evaluated by others (Wallace and Baumeister 2002). Miller and Mesagno (2014) stressed that self-worth is a significant motivating factor among exercisers which can become increasingly maladaptive if dwelled upon excessively. Furthermore, the same authors argued that self-worth becomes noticeably apparent in the form of narcissism. The relationship between narcissism and exercise participation has demonstrated that those exhibiting higher levels of narcissism engage in physical exercise more frequently than those with lower levels of narcissism (Akehurst and Thatcher 2010; Miller and Mesagno 2014; Spano 2001). These findings support self-worth theory and explain why narcissists may engage excessively in exercise (Collins and Stukas 2008; Miller 1992).

Paulhus (2001) investigated narcissism within the framework of the 'Big Five' personality traits (McCrae and Costa 2008) and suggested that narcissism comprises a specific combination of two of the Big Five factors (i.e., high extraversion and a low agreeableness). Paulhus (2001) argued that these two personality dimensions correspond to an emergent personality type that is equivalent to a narcissistic personality. Therefore, in the context of the Big Five, the narcissist can be broadly characterized as a disagreeable extravert. There is considerable evidence to support this two-factor characterization of narcissism with scores on the Narcissistic Personality Inventory (NPI) (Ames et al. 2006) which correlates positively with extraversion and negatively with agreeableness (Rhodewalt and Morf 1995). However, a question that arises with this twofactor combination is related to the unknown behavioral tendencies and characteristics that an individual who exhibits such levels of agreeableness and extraversion would show. In terms of extraversion, Lucas et al. (2000) identified reward sensitivity as a key component so that the rewarding of goals is of most importance to extraverts. With regard to individuals scoring low on agreeableness, these individuals show greater disdain for others and aggressive anger, especially when frustrated (Graziano et al. 2007).

Relationships between personality traits and exercise addiction have emerged in recent literature (Bircher et al. 2017; Costa and Oliva 2012; Gulker et al. 2001; Miller and Mesagno 2014), and it comes as no surprise to find that the personality characteristic of perfectionism has produced very similar findings to narcissism (Miller and Mesagno 2014). Gulker et al. (2001) noted that individuals with a perfectionistic personality type were more likely to engage in excessive bouts of exercise, thus facilitating the development of addictive and maladaptive tendencies toward exercising.

Despite high extraversion and low agreeableness merging as a two-factor combination for narcissism, researchers have investigated the relationship between extraversion and 
agreeableness as separate traits and exercise (Costa and Oliva 2012; Hausenblas and Giacobbi 2004; Mathers and Walker 1999). A few studies have indicated that high extraversion and low agreeableness have an association with exercise (Costa and Oliva 2012; Hausenblas and Giacobbi 2004; Mathers and Walker 1999). Mathers and Walker (1999) reported that nonexercisers were significantly less extraverted compared to the exercisers. However, there was no significant difference in extraversion scores between addicted and non-addicted exercisers. More recently, Costa and Oliva (2012) reported that extraversion was positively associated with tolerance (the need to increase duration, frequency, and intensity in order to obtain the desired affects), time, and intended effects - symptoms that are typical among those addicted to exercise. Consequently, the relationship between extraversion and exercise addiction is unclear. A negative relationship has been found between agreeableness and exercise addiction (Costa and Oliva 2012), further supporting results from previous research reporting that nonexercise-addicted individuals score higher on agreeableness scales compared to exerciseaddicted individuals (Hausenblas and Giacobbi 2004).

Similar to extraversion, there are mixed findings in relation to how neuroticism affects exercise-related behaviors. Some research has found neuroticism to be inversely associated to exercise behaviors (Courneya and Hellsten 1998; Yeung and Hemsley 1997), suggesting that neurotics tend to avoid situations that entail sport and exercise. However, other studies (Costa and Oliva 2012; Hausenblas and Giacobbi 2004) have reported that neuroticism is a key predictor of exercise addiction. Hausenblas and Giacobbi (2004) also suggested that neurotic individuals may tend to exercise in an excessive manner in order to reduce their stress levels and negative emotions as a form of maladaptive coping strategy.

An alternative explanation as to how personality traits can have a positive or negative effect on exercise addiction is provided by the "components" model of addiction developed by Griffiths (2005). This model suggests the existence of basic components that are common to all addictions. Griffiths (2005) provided an explanation as to what an addiction is by arguing that all addictions share a high degree of certain commonalities featuring six key components (i.e., salience, mood modification, tolerance, withdrawal, conflict, and relapse). In cases where individuals fail to meet all six criteria, Griffiths argues that they cannot be operationally defined as having an addiction. Griffiths argues that these components are part of a biopsychosocial process and apply to all addictions whether they involve the ingestion of a drug or not. For any behavior to be considered as addiction (including exercise addiction), there must be long-lasting detrimental effects on an individual's everyday life.

Allegre et al. (2006) conceptualized exercise addiction using the six addiction components. Here, exercise addiction was defined by adverse consequences resulting in conflict and salience, where an individual's thought processes were dominated by exercise and neuroadaptation leading to tolerance and withdrawal components. All of these factors described the negative aspects of excessive exercise. However, mood modification is not necessarily negative. An addiction to exercise could increase positive feelings in that an individual may feel a sense of exhilaration or satisfaction when exercising. Equally, it can be seen as a way of decreasing negative feelings. In this case, exercise would be seen as a means to cope with daily life stressors, which can be understood within the concept of positive addictions (Glasser 1976).

The relationship between the mood modification and withdrawal components in exercise addiction has been investigated by researchers. Mondin et al. (1996) examined the consequences of exercise deprivation in habitual exercisers and found that during the period of exercise interruption, there were some significant mood alterations. These included increased state anxiety, depression, confusion, and tension, leading the authors to conclude that 
deprivation among habitual exercisers could lead to withdrawal symptoms in just one to two days. This has provided support for Griffiths (2005) components model in the area of mood modification and withdrawal. Although individuals report positive feelings after engaging in physical exercise, it starts to have a knock-on effect with regard to the withdrawal component as individuals start to crave the arousal that they experience when participating in exercise.

When examining gender differences among exercise addicts, there is no clear direction as to whether males or females are more prone to becoming addicted to exercise (Kovacsik et al. 2018). In one study, women reported more often than men that they craved exercise and experienced feelings of nervousness and anxiety when they are unable to exercise (Zmijewski and Howard 2003). Another study reported that exercising prevents the emergence of negative feelings (Zmijewski and Howard 2003). Reasons behind why women exercise excessively may be related to how they perceive their body image and potential appearance issues (Davis et al. 2001). This finding relates back to Miller and Mesagno's (2014) self-worth theory because those high in narcissism are more likely to display behaviors related to their appearance in order to improve their self-worth. Emmons (1984) reported that narcissists had a greater motivation to attain a perfect body and had a higher awareness of their appearance. A regression analysis by Davis et al. (2001) demonstrated that narcissism was a unique predictor of greater preoccupation with appearance, even controlling for the effects of perfectionism, neuroticism, and facial attractiveness.

It is not solely females that these results apply to, because over time, males have increasingly been investigated when it comes to body image and attractiveness (Foster et al. 2015). For some males, the attraction to achieve the perfect body has been taken to the extremes, often using exercise to obtain this desire. Multiple studies have unsurprisingly found a high prevalence of exercise addiction in male bodybuilders (Foster et al. 2015; Hurst et al. 2000; Smith and Hale 2004), with a positive and significant relationship found between narcissism and bodybuilding (Carroll 1989). Taken together, gender-based studies indicate that males and females who partake in extreme bouts of physical exercise are more likely to display narcissistic tendencies in order to enhance their appearance.

In light of the aforementioned literature, the purpose of the present pilot study was twofold: (i) to examine the role of narcissism, extraversion, and agreeableness in relation to the amount of exercise an individual undertakes, because these specific traits are often associated with excessive exercising (Costa and Oliva 2012; Hausenblas and Giacobbi 2004; Miller and Mesagno 2014); and (ii) to investigate and explore gender differences among regular exercisers. Given the aims of the present study, the following hypotheses are proposed: (i) exercise addiction will be positively correlated with narcissism; (ii) extraversion and agreeableness will each uniquely contribute as predictors of exercise addiction; and (iii) there will be no significant gender differences in relation to the first two hypotheses.

\section{Method}

\section{Participants}

A total of 114 participants (74 females and 40 males) were recruited in the present study. Participants' ages ranged from 18 to 70 years (mean $=32.4$ years; $\mathrm{SD}=14.9$ years). Of this sample, 102 were regular exercisers (i.e., engaged in exercise at least once a week) and 12 were non-regular exercisers (i.e., engaged in exercise less than once a week). Among the regular 
exercisers, they exercised on average 3.5 times a week $(\mathrm{SD}=1.5)$, with a mean duration of 60.3 min per session $(\mathrm{SD}=31.8)$.

\section{Measures}

Sociodemographic Factors and Exercise Engagement The sample provided data related to key demographic features and patterns of exercise behavior. More specifically, all participants were asked questions about their gender, age, and several questions relating to their engagement and intensity in exercise and sport (see Table 1).

The Exercise Addiction Inventory (Terry et al. 2004) The Exercise Addiction Inventory (EAI) is a six-item psychometric test designed to assess exercise addiction based on a modified version of the components of behavioral addiction (Griffiths 1996). Participants were instructed to rate each of the six statements in relation to the extent each item reflected their current exercise beliefs. All items are rated on a 5-point Likert response option ranging from 1 ("strongly disagree") to 5 ("strongly agree"). The statements were coded so that a higher score reflected a higher degree of exercise addiction behavior. A cut-off score for individuals considered to be "at risk" of exercise addiction was 24 as suggested by Griffiths et al. (2005). In terms of reliability, the EAI has been found to exhibit adequate internal consistency and satisfactory testretest reliability (Griffiths et al. 2005). As for the validity, the EAI displays excellent concurrent validity when compared with the Obligatory Exercise Questionnaire (Pasman and Thompson 1988 ) and the Exercise Addiction Scale (Hausenblas and Downs 2002). In the present study, the EAI has been found to exhibit adequate levels of reliability $(\alpha=0.83)$.

The Narcissistic Personality Inventory (Ames et al. 2006) The Narcissistic Personality Inventory (NPI-16) is a 16-item measure of narcissism which comprises items taken from the larger NPI-40 (Raskin and Terry 1988). Participants are presented with 16 pairs of statements and are requested to select one option from each pair that they think comes closest to describing their feelings about themselves. Narcissistic responses are coded as "1" and non-

Table 1 Sample's main sociodemographic characteristics, narcissism, exercise addiction, agreeableness, and extraversion patterns

\begin{tabular}{ll}
\hline$N$ & 114 \\
Key demographics & \\
Gender & $40(35.1)$ \\
Male $(n, \%)$ & $74(64.9)$ \\
Female $(n, \%)$ & $32.37(14.9)$ \\
Age (years) (mean, SD) & $102(89.5)$ \\
Exercise behaviors & $12(10.5)$ \\
Regular exercisers ( $n, \%)$ & $3.46(1.5)$ \\
Non-regular exercisers ( $n, \%)$ & $60.29(31.8)$ \\
Exercise engagement (regular exercisers, mean (SD)) & $16.54(4.9)$ \\
Exercise intensity (min) (regular exercisers, mean (SD)) & $4.86(1)$ \\
Exercise addiction (mean, SD) & $4.77(1.3)$ \\
Personality variables & $3.18(2.9)$ \\
Agreeableness (mean, SD) & \\
Extraversion (mean, SD) & \\
Narcissism (mean, SD) & \\
\hline
\end{tabular}

"Exercise engagement" corresponds to the variable "exercise sessions per week" and exercise intensity corresponds to the variable "minutes per exercise session" 
narcissistic responses are coded as " 0 " with higher scores reflecting greater narcissistic personality. Ames et al. (2006) carried out a validity analysis to compare the NPI-16 with the full NPI-40. The two measures were highly correlated $(r=0.90 ; p<0.001)$. In the same study (Ames et al. 2006), test-retest reliability for NPI-16 over a five-week interval was assessed, and the results were satisfactory $(r=0.85 ; p<0.01)$ and Cronbach's alpha coefficients of 0.69 and 0.78 were reported at the start and at time two (i.e., five weeks later). In the present study, the NPI-16 was found to exhibit adequate levels of reliability ( $\alpha=0.77)$.

Ten-Item Personality Inventory (Gosling et al. 2003) The Ten-Item Personality Inventory (TIPI) is a ten-item measure of the Big Five personality dimensions (extraversion, agreeableness, conscientiousness, emotional stability, and openness to experience). Participants are instructed to rate the ten descriptors on a 7-point Likert response scale ranging from 1 ("disagree strongly") to 7 ("agree strongly"). Each dimension of the Big Five was represented by two items, one which provided a positive aspect of the dimension and the other which provided a negative aspect. Gosling et al. (2003) provided support for test-retest reliability, and evidence of convergent validity has been previously reported by comparing the TIPI scores to scores obtained from the Big Five Inventory (BFI) (Gosling et al. 2003). In the present study, the TIPI was found to exhibit weaker reliability levels $(\alpha=0.51$.) than the other scales, which was due to the low number of indicators per trait assessed.

\section{Procedure}

The present study was granted ethical approval by the research team's University Ethics Committee before data collection began. Participants were recruited in two ways. The most prominent was via web-based media, direct contact, and e-mails to participants who were asked if they would like to take part in the online survey. The other recruitment method involved using a university research credit scheme where participants would sign up for the study online and select themselves into the sample and be given research credits in return upon completion for their participation. All participants had to provide an informed consent prior to starting the survey and informed that the data collected were anonymous and confidential.

\section{Statistical Analysis}

Statistical analysis comprised (i) general descriptive statistical analyses, (ii) various correlational analyses among the four variables and the sociodemographic questions on the engagement and intensity of exercise, and a (iii) stepwise regression analysis with scores on the EAI as the outcome variable (i.e., dependent variable). All statistical procedures were carried using IBM SPSS Statistics Version 22. All statistical tests adopted a significance level of $p<0.05$.

\section{Results}

\section{Descriptive Statistics}

Table 1 summarizes the participants' main sociodemographic characteristics, narcissism, exercise addiction, agreeableness, and extraversion patterns. The majority of participants 
reported being a regular exerciser $(89.5 \%)$ and who exercised more than three times a week $(\mathrm{M}=3.5, \mathrm{SD}=1.5)$ and averaged exercising for approximately 1 hour in each of these sessions $(\mathrm{M}=60.3, \mathrm{SD}=31.8)$. The means and standard deviations were calculated for exercise addiction $(\mathrm{M}=16.54 ; \mathrm{SD}=4.87)$ and narcissism $(\mathrm{M}=3.18 ; \mathrm{SD}=2.93)$. Means and standard deviations were also calculated for personality trait extraversion $(\mathrm{M}=4.77 ; \mathrm{SD}=1.34)$ and agreeableness $(M=4.86 ; \mathrm{SD}=0.98)$ that were within the TIPI scale (see Table 1$)$.

\section{Correlational Analyses}

Pearson correlation coefficients (r) were computed to investigate the relationships between the variables (i.e., exercise addiction, narcissism, extraversion, and agreeableness). Correlations among participant's engagement and intensity of exercise were also compared against the four scales to see if they had an effect on exercise addiction and personality levels. Several statistically significant correlation coefficients were found among exercise, narcissism, and personality traits from the TIPI (i.e., agreeableness and extraversion) (see Table 2). Most notably, there was a moderate positive correlation between exercise addiction and extraversion $(r=0.37, p<0.001)$ indicating that participants with higher scores on the Exercise Addiction Inventory tended to score higher on the extraversion questions in the TIPI. However, the association between exercise addiction and agreeableness $(r=-0.02, p=0.8)$ was not statistically significant. There was a significant negative correlation between narcissism scores and agreeableness scores $(r=-44, p<0.001)$ indicating that participants exhibiting higher levels of narcissism had lower levels of agreeableness. Exercise intensity $(r=0.28, p=0.003)$ and exercise engagement $(r=0.53, p<0.001)$ scores indicated that the higher the intensity and engagement of exercise that participants undertook, the higher they scored on the EAI. A significant positive correlation was found between extraversion and exercise engagement $(r=$ $0.24, p=0.01$ ) indicating that participants who engaged in a high number of exercise sessions a week were more likely to score highly on the extraversion questions.

\section{Correlational Gender Differences}

Pearson correlation coefficients were also computed separately for female (Table 3 ) and male (Table 4) participants. Correlation between narcissism and agreeableness in males and females proved similar. Among females, scores indicated that the higher participants scored on the narcissism scale, the lower they scored on the agreeableness scale $(r=-0.38, p=0.001)$. Likewise, males displayed a moderate significant negative correlation between narcissism and

Table 2 Inter-correlations among exercise and personality variables for total sample $(N=114)$

\begin{tabular}{|c|c|c|c|c|c|c|}
\hline Variable & 1 & 2 & 3 & 4 & 5 & 6 \\
\hline Narcissism (1) & 1 & $0.24 *$ & $0.41 * *$ & $-0.44^{* *}$ & 0.14 & 0.05 \\
\hline Exercise addiction (2) & & 1 & $0.37 * *$ & -0.02 & $0.53 * *$ & $0.28 * *$ \\
\hline Extraversion (3) & & & 1 & $-0.25 * *$ & $0.24 * *$ & $0.29 * *$ \\
\hline Agreeableness (4) & & & & 1 & 0.10 & -0.001 \\
\hline Exercise engagement (5) & & & & & 1 & .10 \\
\hline Exercise intensity (6) & & & & & & 1 \\
\hline
\end{tabular}

"Exercise engagement" corresponds to the variable "exercise sessions per week" and exercise intensity corresponds to the variable "minutes per exercise session"

$* * p<0.01 ; * p<0.05$ 
Table 3 Inter-correlations among exercise and personality variables for female participants $(N=74)$

\begin{tabular}{|c|c|c|c|c|c|c|}
\hline Variable & 1 & 2 & 3 & 4 & 5 & 6 \\
\hline Narcissism (1) & 1 & 0.21 & $0.39 * *$ & $-0.38 * *$ & 0.07 & -0.08 \\
\hline Exercise addiction (2) & & 1 & $0.28 *$ & -0.05 & $0.51 * *$ & 0.14 \\
\hline Extraversion (3) & & & 1 & -0.16 & $0.29 *$ & 0.17 \\
\hline Agreeableness (4) & & & & 1 & 0.03 & 0.07 \\
\hline Exercise engagement (5) & & & & & 1 & 0.10 \\
\hline Exercise intensity (6) & & & & & & 1 \\
\hline
\end{tabular}

"Exercise engagement" corresponds to the variable "exercise sessions per week" and exercise intensity corresponds to the variable "minutes per exercise session"

$* * p<0.01 ; * p<0.05$

agreeableness traits $(r=-0.51, p=0.001)$ indicating the more narcissistic they are, the less agreeable they tend to be. Results were not statistically significant for males $(r=-0.01, p=$ $0.945)$ and females $(r=-0.05, p=0.656)$ for the agreeable personality type in the TIPI, when compared to exercise addiction scores. For females, higher levels of exercise addiction were associated with higher levels of extraversion $(r=0.28, p=0.014)$, with males displaying similar results $(r=0.48, p=0.002)$. These scores indicated that for both males and females, the higher they scored on the exercise addiction scale, the more likely they were to exhibit high levels of extraversion.

\section{Regression Analysis}

Based on the findings from the correlational analyses, gender, exercise engagement, exercise intensity, extraversion, agreeableness, and narcissism were modeled into a non-hierarchical stepwise multiple regression analysis to predict exercise addiction. The final model was reached after three steps, and out of the five predictors, only three (i.e., exercise engagement, extraversion, and exercise intensity) remained statistically significant in the final model, with gender, agreeableness, and narcissism being excluded from the model as they did not statistically predict exercise addiction. The final model including the three predictors was statistically significant $(f[1,110]=4.51, p=0.036)$ and accounted for approximately $36 \%$ of the total variance of exercise addiction scores $\left(R^{2}=0.37\right.$, adjusted $\left.R^{2}=0.36\right)$.

Exercise addiction was primarily predicted by how many times participants engaged in exercise a week $(\beta=0.46, p<0.05)$ followed by extraversion scores $(\beta=0.21, p<0.05)$ and exercise intensity $(\beta=0.17, p<0.05)$ to a lesser extent. Table 5 shows the unstandardized and

Table 4 Inter-correlations among exercise and personality variables for male participants $(N=40)$

\begin{tabular}{|c|c|c|c|c|c|c|}
\hline Variable & 1 & 2 & 3 & 4 & 5 & 6 \\
\hline Narcissism (1) & 1 & $0.35^{*}$ & $0.51 * *$ & $-0.51^{* *}$ & 0.18 & $0.32 *$ \\
\hline Exercise addiction (2) & & 1 & $0.48 * *$ & -0.01 & $0.59 * *$ & $0.52 * *$ \\
\hline Extraversion (3) & & & 1 & $-0.36^{*}$ & 0.21 & $0.50 * *$ \\
\hline Agreeableness (4) & & & & 1 & 0.19 & -0.12 \\
\hline Exercise engagement (5) & & & & & 1 & 0.11 \\
\hline Exercise intensity (6) & & & & & & 1 \\
\hline
\end{tabular}

"Exercise engagement" corresponds to the variable "exercise sessions per week" and exercise intensity corresponds to the variable "minutes per exercise session"

$* * p<0.01 ; * p<0.05$ 
Table 5 Stepwise multiple linear regression of the relationship between exercise addiction and key-related predictors

\begin{tabular}{|c|c|c|c|c|c|c|c|c|c|c|c|c|}
\hline \multirow[b]{2}{*}{ Predictors } & \multicolumn{4}{|c|}{ Step 1} & \multicolumn{4}{|c|}{ Step 2} & \multicolumn{4}{|c|}{ Step 3} \\
\hline & $B$ & SE & $\beta$ & $t$ & $B$ & SE & $\beta$ & $t$ & $B$ & SE & $\beta$ & $t$ \\
\hline Exercise engagement & 1.60 & 0.24 & $0.53 * *$ & 6.61 & 1.41 & 0.24 & $0.46^{* *}$ & 5.93 & 1.40 & 0.24 & $0.46^{*}$ & 5.96 \\
\hline Extraversion & & & & & 0.95 & 0.29 & $0.26^{*}$ & 3.30 & 0.77 & 0.29 & $0.21 *$ & 2.63 \\
\hline Exercise intensity & & & & & & & & & 0.03 & 0.01 & $0.17 *$ & 2.12 \\
\hline \multicolumn{13}{|l|}{ Model summary } \\
\hline Variance explained by model & \multirow{2}{*}{\multicolumn{4}{|c|}{$R^{2}=0.283(28.3 \%)$}} & \multirow{2}{*}{\multicolumn{4}{|c|}{$\begin{array}{l}R^{2}=0.347(34.7 \%) \\
\Delta R^{2}=0.064(6.4 \%)\end{array}$}} & \multirow{2}{*}{\multicolumn{4}{|c|}{$\begin{array}{l}R^{2}=0.372(37.2 \%) \\
\Delta R^{2}=0.026(2.6 \%)\end{array}$}} \\
\hline $\begin{array}{l}\text { Change in variance by } \\
\text { next step }\end{array}$ & & & & & & & & & & & & \\
\hline $\begin{array}{l}\text { Statistical significance } \\
\text { of model }\end{array}$ & \multirow{2}{*}{\multicolumn{4}{|c|}{$F(1,112)=44.11 * *$}} & \multicolumn{4}{|c|}{$F(2,111)=29.45 * *$} & \multicolumn{4}{|c|}{$F(3,110)=21.76^{* *}$} \\
\hline $\begin{array}{l}\text { Statistical significance } \\
\text { of steps }\end{array}$ & & & & & \multicolumn{4}{|c|}{$\Delta F(1,111)=10.90 *$} & \multicolumn{4}{|c|}{$\Delta F(1,110)=4.51^{*}$} \\
\hline
\end{tabular}

Outcome: exercise addiction. "Exercise engagement" corresponds to the variable "exercise sessions per week" and exercise intensity corresponds to the variable "minutes per exercise session." The final model (i.e., step 3) excluded the following variables due to their low and non-significant predictive power in the outcome variable (i.e., exercise addiction): narcissism, agreeableness, and gender

$B$, unstandardized regression coefficient; $S E$, standard error; $\beta$, standardized regression coefficient; $R^{2}$, R square; $\Delta R^{2}, \mathrm{R}^{2}$ change

$* * p<0.01 ; * p<0.05$

standardized regression coefficients of the three predictors alongside their correlation coefficients with exercise addiction and their squared semi-partial correlations. Overall, exercise engagement provided the strongest weight in the model followed by extraversion then exercise intensity. As indexed by the semi-partial correlations, the unique variance of each variable predictor is explained. Exercise engagement, extraversion, and exercise intensity accounted for approximately $21.5 \%, 14 \%$, and $7.6 \%$ of the variance of exercise addiction. From the obtained standardized beta coefficients in the present model, exercise engagement, extraversion, and exercise intensity each contributed $46.4 \%, 21.3 \%$, and $16.8 \%$ respectively of the total variance of exercise addiction when holding all other independent variables constant.

When examining the predicted change in the outcome variable (i.e., exercise addiction) for every unit increase in each predictor variable, the unstandardized regression coefficients indicate this change. Exercise engagement was associated with a partial regression coefficient of 1.4, which means that for every additional point that was scored within this variable, there would be an expected increase of approximately 1.4 points on exercise addiction levels. For extraversion, every additional point in this variable predicts an increase of 0.8 points on exercise addiction levels, while an additional point on exercise intensity levels leads to an expected increase of 0.03 points on exercise addiction levels.

\section{Discussion}

The purpose of the present pilot study was to investigate two important research questions. The first sought to examine the role of key personality traits (i.e., narcissism, extraversion, and agreeableness) in relation to the amount of exercise an individual undertakes. The second was to investigate any gender differences among regular exercisers. Based purely on exercise 
addiction scores, results demonstrated very few participants were at risk of exercise addiction. Terry et al. (2004) proposed a cut-off point in which scores would be classified as asymptomatic, symptomatic, or at risk of exercise addiction. In the present study, only $7 \%$ were scored to be "at risk" of exercise addiction $(n=8), 75 \%$ were "symptomatic" $(n=85)$, and $12 \%$ were "asymptomatic" ( $n=21)$, further suggesting that most of the participants in the present study would be considered as just casual exercisers with very few participants being identified as being at risk of exercise addiction. This low prevalence rate of exercise addiction supports previous studies using the EAI (e.g., Griffiths et al. 2015; Mónok et al. 2012; Szabo and Griffiths 2007) and suggests that some studies may be assessing exercise commitment and dependence rather than an actual exercise addiction (e.g., Costa and Oliva 2012; Hausenblas and Giacobbi 2004; Miller and Mesagno 2014; Spano 2001).

In relation to the first research question examining narcissism, a statistically significant relationship was observed between narcissism and exercise addiction. Participants displaying high levels of narcissism were more likely to show exercise addiction symptoms. Although previous research examining narcissism and exercise addiction is minimal, Spano (2001) reported there was an association between narcissism and greater involvement in physical activity. The present study further expands Spano's (2001) research because the findings of the present study indicated that exercise may be more addictive for those who are perceived to have a narcissistic personality type. This finding corroborates previous research suggesting that it is not uncommon for narcissists to excessively exercise in order to increase their sense of self-worth and appearance (Miller and Mesagno 2014; Wallace and Baumeister 2002). Consequently, the need to maintain high feelings of self-worth could manifest into an addiction to exercising (Miller and Mesagno 2014).

When the relationship between narcissism and exercise addiction was re-examined, after separating participants by their gender and examining the second research question, the relationship between narcissism and exercise addiction was found in males only. This finding lends support to Brown (2000) and Carroll (1989) who suggested that groups of males who exercise excessively are more likely to be narcissistic. These studies indicate high levels of narcissism and exercise addiction symptoms may typically co-exist in males. Results suggest that the physical and mental rewards associated with exercise (i.e., increased sense of self-worth, appearance, and fitness) may lead narcissistic males to exercise in a more excessive way which in consequence could manifest in an addiction to exercise.

Furthermore, the present correlational findings indicated that there was no significant relationship between agreeableness and exercise addiction; therefore, the second hypothesis was not supported (i.e., agreeableness will be one of the predictors of exercise addiction). Results from the present study do not fall in line with the findings of previous studies which have found agreeableness to be a predictor of exercise addiction symptoms (Costa and Oliva 2012; Hausenblas and Giacobbi 2004). Despite the paucity of research concerning agreeableness, research suggests that individuals low in agreeableness tend to be unfriendly and competitive, resulting in excessive exercise in order to satisfy their competitive nature (Hausenblas and Giacobbi 2004). Based on the findings presented here, it appears further research is necessary in order to confirm whether agreeableness is one of the predictors of exercise addiction.

Despite the lack of effect that agreeableness had on exercise addiction, high scores reported on the narcissism and extraversion scales resulted in a significant negative correlation of agreeableness, remaining consistent among males and females. This provides additional support for the "emergent personality type" in which Paulhus (2001) argued was equivalent to a narcissistic personality type and comprises high extraversion and low agreeableness. Like 
the findings of the present study, considerable evidence supports this two-factor characterization of narcissism with scores on the NPI correlating positively with extraversion and negatively with agreeableness, thus forming a "disagreeable extravert" personality type (Ames et al. 2006; Rhodewalt and Morf 1995).

Results from this and previous studies demonstrate that extraversion appears to be an extremely relevant individual difference in exercise addiction. For both males and females, analysis indicated that high extraversion scores correlated significantly with high exercise addiction scores. This finding confirms previous research showing that individuals reporting low exercise engagement may be less extraverted and more agreeable when compared to individuals who exercise regularly (Hausenblas and Giacobbi 2004). In light of the second hypothesis (i.e., extraversion will be a predictor of exercise addiction), the results from the multiple regression analysis yielded a model with three predictors (i.e., exercise engagement, extraversion, and exercise intensity) which accounted for approximately $36 \%$ of the variance. Despite one demographic variable (i.e., exercise engagement) explaining the highest percent of the variance (i.e., 21.5\%), extraversion proved to be the second best predictor accounting for $14 \%$ of the variance. Based upon these observations, extraversion as a predictor of exercise addiction remains consistent with previous findings (e.g., Costa and Oliva 2012; Courneya and Hellsten 1998; Mathers and Walker 1999; Yeung and Hemsley 1997).

In summary, results from the present study are in line with the findings of Costa and Oliva (2012) in that extraversion appears to be a relevant personality trait associated with exercise addiction. The association of a narcissistic personality type displaying exercise addiction symptoms supports recent literature (Miller and Mesagno 2014) while agreeableness appears not to be a personality trait that has a significant impact on exercise addiction behaviors in the present study. This is in stark contrast to the previous research (Costa and Oliva 2012; Hausenblas and Giacobbi 2004) who reported a negative association between high levels of agreeableness and low levels of exercise addiction.

The present study is not without potential limitations. First, the sample size and population should be taken into account in terms of limited generalizability to the wider population as a large proportion of the sample comprised university students. Second, the use of the TIPI may have weakened the correlations between the personality variables, as shorter scales tend to be less reliable (Gosling et al. 2003), with the present study exhibiting a lower than desired reliability score for the personality measure adopted $(\alpha=0.51)$. Gosling et al. (2003) explain that it is almost impossible to score high alphas on the TIPI scale because of the design and because it assesses broad domains with only two items per personality trait. For future studies examining personality in more detail, it is suggested that other more comprehensive personality assessment tools such as the 44-item Big Five inventory (John and Srivastava 1999) are used or the 60-item NEO Five-Factor Inventory (Costa and McCrae 1992). Third, the NPI was susceptible to response bias due to the nature of what it assesses. Since narcissism is not a particularly desirable quality to have, highly narcissistic participants may have downplayed their narcissistic tendencies in the self-report method of response. This could lead to reduced accuracy in the relationships between the variables. Self-report measures are also known to have other well-known biases (such as memory recall biases). Finally, the demographic variables assessing exercise engagement and intensity were assessed by non-standardized psychometric tools. For that reason, the strength of the association between the NPI responses and the other variables should be interpreted with caution.

Due to the serious implications exercise addiction can have on an individual's physical and psychological wellbeing, it is important to examine which determinants play a contributory 
role in this behavioral addiction. The present study found that individuals reporting high exercise addiction scores are in general more extraverted and narcissistic compared to those with low exercise addiction scores. For future studies examining the role of personality on exercise addiction, it is suggested that the use of standardized psychometric tools should be employed when investigating the association between the variables, as an alternative to selfdevised questions. Furthermore, the use of a larger and more diverse and generalized sample should be used. The findings from the present study indicate the potential to identify those susceptible to exercise addiction through the identification of co-existing narcissistic and extraverted traits in exercisers.

Compliance with Ethical Standards The present study was granted ethical approval by the research team's University Ethics Committee before data collection began.

Conflict of Interest The authors declare that they have no conflict of interest.

Open Access This article is distributed under the terms of the Creative Commons Attribution 4.0 International License (http:/creativecommons.org/licenses/by/4.0/), which permits unrestricted use, distribution, and reproduction in any medium, provided you give appropriate credit to the original author(s) and the source, provide a link to the Creative Commons license, and indicate if changes were made.

\section{References}

Akehurst, S., \& Thatcher, J. (2010). Narcissism, social anxiety and self-presentation in exercise. Personality and Individual Differences, 49(2), 130-135. https://doi.org/10.1016/j.paid.2010.03.021.

Allegre, B., Souville, M., Therme, P., \& Griffiths, M. (2006). Definitions and measures of exercise dependence. Addiction Research and Theory, 14, 631-646. https://doi.org/10.1080/16066350600903302.

American Psychiatric Association. (2013). Diagnostic and statistical manual of mental disorders (5th ed.). Arlington: American Psychiatric Association.

Ames, D. R., Rose, P., \& Anderson, C. P. (2006). The NPI-16 as a short measure of narcissism. Journal of Research in Personality, 40, 440-450. https://doi.org/10.1016/j.jrp.2005.03.002.

Bircher, J., Kasos, K., Demetrovics, Z., Griffiths, M. D., \& Szabo, A. (2017). Exercise addiction and personality: A two-decade systematic review of the empirical literature (1995-2016). Baltic Journal of Sports and Health Sciences, 3(106), 19-33.

Brown, L. B. (2000). Powerful physiques, vulnerable psyches: Narcissism, body image and masculinity in male bodybuilders - PsycINFO - ProQuest. Dissertation Abstracts International: Section B: The Sciences and Engineering, 61(7-B), 3833.

Carroll, L. (1989). A comparative study of narcissism, gender, and sex-role orientation among bodybuilders, athletes, and psychology students. Psychological Reports, 64, 999-1006.

Collins, D. R., \& Stukas, A. A. (2008). Narcissism and self-presentation: The moderating effects of accountability and contingencies of self-worth. Journal of Research in Personality, 42(6), 1629-1634. https://oi. org/10.1016/j.jrp.2008.06.011.

Costa, P., \& McCrae, R. (1992). Revised NEO personality (NEOPI-R) and NEO five factor inventory (NEO-FFI) professional manual. Odessa: Psychological Assessment Resources.

Costa, S., \& Oliva, P. (2012). Examining relationship between personality characteristics and exercise dependence. Review of Psychology, 19(1), 5-12.

Courneya, K. S., \& Hellsten, L.-A. M. (1998). Personality correlates of exercise behavior, motives, barriers and preferences: An application of the Five-Factor model. Personality and Individual Differences, 24(5), 625633. https://doi.org/10.1016/S0191-8869(97)00231-6.

Davis, C., Dionne, M., \& Shuster, B. (2001). Physical and psychological correlates of appearance orientation. Personality and Individual Differences, 30(1), 21-30. https://doi.org/10.1016/S0191-8869(00)00006-4.

Emmons, R. (1984). Factor analysis and construct validity of the narcissistic personality inventory. Journal of Personality Assessment, 48(3), 291-300. https://doi.org/10.1207/s15327752jpa4803.

Foster, A. C., Shorter, G. W., \& Griffiths, M. D. (2015). Muscle dysmorphia: Could it be classified as an addiction to body image? Journal of Behavioral Addictions, 4, 1-5. https://doi.org/10.1556/JBA.3.2014.001. 
Fox, K. R. (1999). The influence of physical activity on mental well-being. Public Health Nutrition, 2(3A), 411418. https://doi.org/10.1017/S1368980099000567.

Glasser, W. (1976). Positive addictions. New York: Harper \& Row.

Gosling, S. D., Rentfrow, P. J., \& Swann, W. B. (2003). A very brief measure of the Big-Five personality domains. Journal of Research in Personality, 37(6), 504-528. https://doi.org/10.1016/S0092-6566(03 )00046-1.

Gossop, M. R., \& Eysenck, S. B. G. (1980). A further investigation into the personality of drug addicts in treatment. British Journal of Addiction, 75(3), 305-311. https://doi.org/10.1111/j.1360-0443.1980.tb01384.x.

Graziano, W. G., Habashi, M. M., Sheese, B. E., \& Tobin, R. M. (2007). Agreeableness, empathy, and helping: A person $\times$ situation perspective. Journal of Personality and Social Psychology, 93(4), 583-599. https://doi. org/10.1037/0022-3514.93.4.583.

Griffiths, M. (1996). Behavioural addiction: An issue for everybody? Journal of Workplace Learning, 8(3), 1925. https://doi.org/10.1108/13665629610116872.

Griffiths, M. (2005). A "components" model of addiction within a biopsychosocial framework. Journal of Substance Use, 10(4), 191-197. https://doi.org/10.1080/14659890500114359.

Griffiths, M. D., Szabo, A., \& Terry, A. (2005). The exercise addiction inventory: A quick and easy screening tool for health practitioners. British Journal of Sports Medicine, 39(6), 30. https://doi.org/10.1136 /bjsm.2004.017020.

Griffiths, M. D., Urbán, R., Demetrovics, Z., Lichtenstein, M. B., de la Vega, R., Kun, B., Ruiz-Barquín, R., Youngman, J., \& Szabo, A. (2015). A cross-cultural re-evaluation of the Exercise Addiction Inventory (EAI) in five countries. Sports Medicine Open, 1, 5. https://doi.org/10.1186/s40798-014-0005-5.

Gulker, M. G., Laskis, T. A., \& Kuba, S. A. (2001). Do excessive exercisers have a higher rate of obsessivecompulsive symptomatology? Psychology, Health \& Medicine, 6(4), 387-398. https://doi.org/10.1080 $/ 13548500120087024$.

Hausenblas, H. A., \& Downs, D. S. (2002). Relationship among body image, exercise behavior, and exercise dependence symptoms. International Journal of Eating Disorders, 32(2), 169-172. https://doi.org/10.1002 /eat.10071.

Hausenblas, H. A., \& Giacobbi, P. R. (2004). Relationship between exercise dependence symptoms and personality. Personality and Individual Differences, 36(6), 1265-1273. https://doi.org/10.1016/S01918869(03)00214-9.

Hurst, R., Hale, B., Smith, D., \& Collins, D. (2000). Exercise dependence, social physique anxiety, and social support in experienced and inexperienced bodybuilders and weightlifters. British Journal of Sports Medicine, 34(6), 431-435. https://doi.org/10.1136/bjsm.34.6.431.

John, O. P., \& Srivastava, S. (1999). The Big Five Trait taxonomy: History, measurement, and theoretical perspectives. In L. A. Pervin \& O. P. John (Eds.), Handbook of personality: Theory and research (pp. 102138). New York: Guilford Press. https://doi.org/10.1007/s13398-014-0173-7.2.

Kovacsik, R., Griffiths, M. D., Pontes, H. M., Soós, I., de la Vega, R., Ruíz-Barquín, R., Demetrovics, Z., \& Szabo, A. (2018). The role of passion in exercise addiction, exercise volume, and exercise intensity in longterm exercisers. International Journal of Mental Health and Addiction. https://doi.org/10.1007/s11469-0189880-1.

Lucas, R. E., Diener, E., Grob, A., Suh, E. M., \& Shao, L. (2000). Cross-cultural evidence for the fundamental features of extraversion. Journal of Personality and Social Psychology, 79(3), 452-468. https://doi. org/10.1037/0022-3514.79.3.452.

Mathers, S., \& Walker, M. B. (1999). Extraversion and exercise addiction. Journal of Psychology, 133(1), 125128. https://doi.org/10.1080/00223989909599727.

McCrae, R. R., \& Costa, P. T. Jr. (2008). The five-factor theory of personality. In O. P. John, R. W. Robins, \& L. A. Pervin (Eds.), Handbook of personality: Theory and research (3rd ed., pp. 159-181). New York: Guilford Press. https://doi.org/10.1007/978-1-4615-0763-5_11.

Miller, I. J. (1992). Interpersonal vulnerability and narcissism: A conceptual continuum for understanding and treating narcissistic psychopathology. Psychotherapy: Theory, Research, Practice, Training, 29(2), 216-224. https://doi.org/10.1037/0033-3204.29.2.216.

Miller, K. J., \& Mesagno, C. (2014). Personality traits and exercise dependence: Exploring the role of narcissism and perfectionism. International Journal of Sport and Exercise Psychology, 12(4), 368-381. https://doi. org/10.1080/1612197X.2014.932821.

Mondin, G. W., Morgan, W. P., Piering, P. N., Stegner, A. J., Stotesbery, C. L., Trine, M. R., \& Wu, M. Y. (1996). Psychological consequences of exercise deprivation in habitual exercisers. Medicine \& Science in Sports \& Exercise, 28(9), 1199-1203. https://doi.org/10.1097/00005768-199609000-00018.

Mónok, K., Berczik, K., Urbán, R., Szabó, A., Griffiths, M. D., Farkas, J., Magi, A., Eisinger, A., Kurimay, T., Kökönyei, G., Kun, B., Paksi, B., \& Demetrovics, Z. (2012). Psychometric properties and concurrent 
validity of two exercise addiction measures: A population wide study in Hungary. Psychology of Sport and Exercise, 13, 739-746. https://doi.org/10.1016/j.psychsport.2012.06.003.

Pasman, L., \& Thompson, J. K. (1988). Body image and eating disturbance in obligatory runners, obligatory weightlifters, and sedentary individuals. International Journal of Eating Disorders, 7(6), 759-769. https://doi.org/10.1002/1098-108X.

Paulhus, D. L. (2001). Normal narcissism: Two minimalist accounts. Psychological Inquiry, 12(4), $228-230$.

Raskin, R., \& Terry, H. (1988). A principal-components analysis of the Narcissistic Personality Inventory and further evidence of its construct validity. Journal of Personality and Social Psychology, 54(5), 890-902. https://doi.org/10.1037/0022-3514.54.5.890.

Reilly, C., \& Smith, N. (2013). The evolving definition of pathological gambling in the DSM-5. National Center for Responsible Gaming, 1, 1-6.

Rhodewalt, F., \& Morf, C. C. (1995). Self and interpersonal correlates of the Narcissistic Personality Inventory: A review and new findings. Journal of Research in Personality, 29(1), 1-23. https://doi.org/10.1006 /jrpe.1995.1001.

Smith, D., \& Hale, B. (2004). Validity and factor structure of the bodybuilding dependence scale. British Journal of Sports Medicine, 38(2), 177-181. https://doi.org/10.1136/bjsm.2002.003269.

Spano, L. (2001). The relationship between exercise and anxiety, obsessive-compulsiveness, and narcissism. Personality and Individual Differences, 30(1), 87-93. https://doi.org/10.1016/S0191-8869(00)00012-X.

Szabo, A., \& Griffiths, M. D. (2007). Exercise addiction in British sport science students. International Journal of Mental Health and Addiction, 5, 25-28. https://doi.org/10.1007/s11469-006-9050-8.

Terry, A., Szabo, A., \& Griffiths, M. (2004). The exercise addiction inventory: A new brief screening tool. Addiction Research and Theory, 12(5), 489-499. https://doi.org/10.1080/16066350310001637363.

Wallace, H. M., \& Baumeister, R. F. (2002). The performance of narcissists rises and falls with perceived opportunity for glory. Journal of Personality and Social Psychology, 82(5), 819-834. https://doi.org/10.1037 /0022-3514.82.5.819.

Yeung, R. R., \& Hemsley, D. R. (1997). Personality, exercise and psychological well-being: Static relationships in the community. Personality and Individual Differences, 22(1), 47-53. https://doi.org/10.1016/S01918869(96)00158-4.

Zmijewski, C. F., \& Howard, M. O. (2003). Exercise dependence and attitudes toward eating among young adults. Eating Behaviors, 4(2), 181-195. https://doi.org/10.1016/S1471-0153(03)00022-9. 